Svitlana Kokhan - Antonina Moskalenko - Oleg Drozdivskyi*

\title{
QUANTITATIVE LAND SUITABILITY MAPPING FOR CROP CULTIVATION
}

Developing the structure of geodatabase and knowledge base to provide quantitative mapping of land suitability for cultivation the main crops has been shown in the research. The general model and catalogs of knowledge base were designed that are structuring and formalizing information for creating thematic and complex maps and geomodels.

The real world spatial problems give rise to multi-criteria decision-making based on geographical information systems (GIS). The GIS environment provides both aggregation and spatial analysis of various georeferenced data. In this paper, the two approaches of multi-criteria evaluation (MCE) are represented - overlaying with the AND operation and the lowest score assignment on one criterion. An example of multi-attribute decision analysis is done using criteria for the crop suitability assessment. A comparison of those two approaches has been made, based on results of the land-use suitability mapping for the study crops - winter wheat, sunflower and corn. The results demonstrated that at certain locations, a range of criteria values, according to the AND operations had the lower applicability and less flexibility than according to the second approach, based on the lowest score assignment on one criterion. Designed maps characterize the threshold status of the soil quality to provide yields of studied crops on certain areas.

A set of land suitability maps, designed as quantitative models of integration of environmental, soil and climatic conditions, would be very effective to manage the complex decisions under the crop cultivation.

Keywords: knowledge base, geodatabase, land suitability, geoinformation mapping

\section{Introduction}

Ukraine, being rich in unique land resources, has favorable climatic and soil conditions for cultivation of sustainable crop yields. However, both anthropogenic activity and intensification of agricultural production have a tendency to grow, what leads to increase of a soil degradation.

In order to enhance the efficiency of utilizing agricultural resources and improve land use planning, different approaches are applied. The climatic and soil conditions of territories are taken into consideration in majority of research.

Land suitability is the fitness of a given type of land for a specified kind of land use [1]. The aim of land evaluation is to select the optimum land-use according to the purpose and scale of land units. Assessment and grouping of certain areas, in terms of their suitability for proper use, is based on mapping a suitability classes or indexes. Physical resources (e.g. climate, vegetation, water, hydrology, landform and soil), human and capital resources are the major kinds of the land-use resources [2].

A set of the land-use suitability maps, designed as quantitative models of integration environmental, soil and climatic conditions, would be very effective to manage complex decisions in land-use planning.

Research in land suitability assessment combines different approaches, techniques and methods, represented in publications [3], [4], [5], [6]. The multi-criteria decision-making (MCDM) has also become one of the most useful methods for land-use and environmental planning [3], [7]. It is primarily concerned with how to combine the information from several criteria to form a single index of evaluation [8].

A number of multi-criteria decision rules implemented in the geographic information system (GIS) environment, including the weighted linear combination (WLC) or weighted summation/ Boolean overlay methods, have been used [9].

There has been an approach for land use planning in sustainable rural systems with a conceptual model, a process model and a future model [10]. The processes of developing soil erosion and soil salinity, as well, the increase in plowing arable lands in the modern Ukrainian agriculture for the latest decades, have been an issue of soil rational use and protection.

In order to ensure the effective quantitative land suitability evaluation and design a set of land suitability maps for crop cultivation, an information system is required, which would ensure solutions of the problem of land rational use and land protection.

\section{Research methodology}

The approach of geoinformation mapping, providing the development of formal geographic and cartographic knowledge, is based on application of geodatabases. The knowledge is obtained with heterogeneous geodata that is being basic in developing an appropriate information system [11]

The process of designing thematic maps requires both an improvement of geodatabase sectoral models and development of knowledge base models. Research on agricultural land monitoring

\footnotetext{
* Svitlana Kokhan, Antonina Moskalenko, Oleg Drozdivskyi

Department of Geoinformatics and Aerospace Research of the Earth, National University of Life and Environmental Sciences of Ukraine, Ukraine E-mail: kokhan_s@nubip.edu.ua
} 


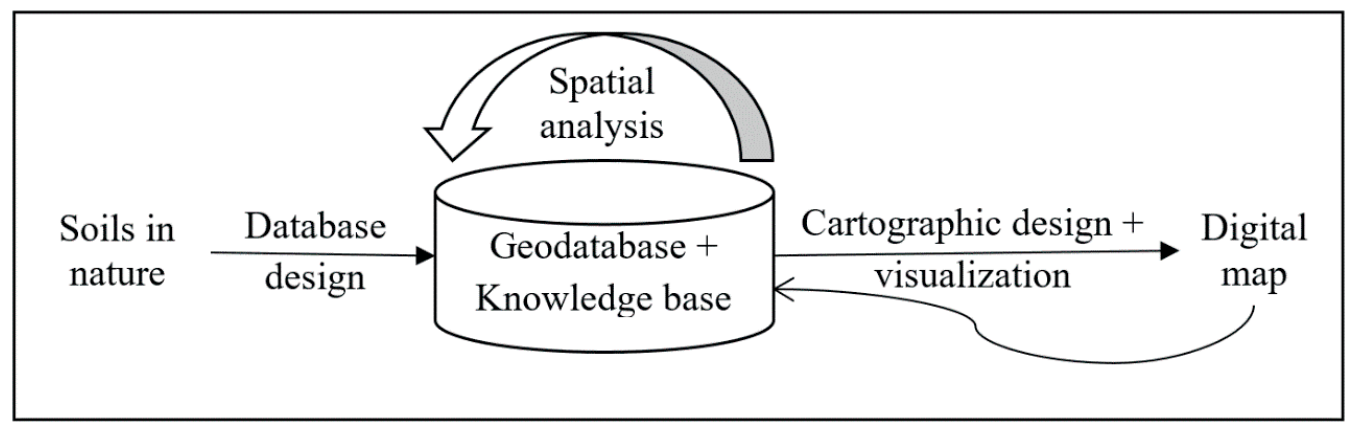

Figure 1 Scheme of geoinformation mapping system for quantitative land suitability assessment

and approaches to the development of GIS and geodatabases were considered in papers [12], [13], [14], [15]. The development of knowledge base structure with UML is represented in articles [6], [12], [16], [17], [18], [19].

The aim of the current research is to develop the structure of geodatabase and knowledge base to provide quantitative mapping of land suitability for main crops cultivation in the Northern Forest-Steppe of Ukraine. Basic structural components of geodatabase and the knowledge base should be explained to map quantitative land suitability sub-classes.

The research comprises of the following stages:

- designing conceptual, logical and physical models of geodatabase as basic components of geoinformation mapping system;

- determining the general structure of information blocks; development of a general model and catalogs of knowledge base;

- physical realization of the trial version of geoinformation mapping system using attribute and spatial data for land suitability evaluation in the Northern Forest-Steppe of Ukraine.

Land suitability evaluation for the crop production involves the interpretation of data related to climate, soils, slopes of the territory, type of crops, etc., in order to provide crop requirements to optimal growth conditions.

The Food and Agricultural Organisation [1] proposed land evaluation in terms of two broad classes, "suitable" (S) and "not suitable" $(\mathrm{N})$, based on the suitability of land characteristics to various conditions. Those two are further sub-classified as follows:

Class S1 - Highly suitable: land having no significant limitations for sustained applications to a given use. Minor limitations are applied that would not significantly reduce the productivity.

Class S2 - Moderately suitable: land having limitations that in the aggregate are moderately severe for sustained application to a given use and may reduce the productivity marginally. Those lands have slight limitations and/or no more than three moderate limitations.

Class S3 - Marginally suitable: land with limitations that in the aggregate are severe for sustained application to a given use and as such reduce productivity significantly, but is still marginally economical. Those lands have more than three moderate limitations and/or more than one severe limitation that, however, does not preclude their use for the specified purposes.
An approach, described in [20], based on five sub-classes of land suitability was applied in this research. According to this classification, the arable lands in Ukraine are grouped into sub-classes in terms of the suitability of land characteristics to provide the crop requirements to soil and climatic conditions. Following to this approach, the input data comprises of digital map of soil agricultural production groups and topographic factors. Combining these initial data with the soil quality characteristics (e.g. $\mathrm{pH}$ and available nutrients), quantitative land suitability maps for the study area have been developed. To map a suitability sub-classes for study crops, the two approaches were used - overlaying with the AND operation and the lowest score assignment on one criterion. The GIS software was used for data analysis and mapping (ArcGIS 10.3), as well as for supporting spatial decisions.

For the Boolean intersection and overlay, all the criteria are assumed to be constraints and the result is the AND or Boolean minimum operation. This combination technique provides the lowest possible risk, since the only areas considered suitable in the result are those considered suitable in all the criteria.

In weighted linear combination method, criteria may include both weighted factors and constraints. Factor weights are very important in the WLC because they determine how individual factors will tradeoff relative to each other. Each criterion can be assigned a specific weight that reflects it importance relative to other criteria under consideration [5]. Derivation of weights is a central step in defining the decision maker's preferences. This procedure is sometimes too complicated. An approach that is more flexible is used in this study. It is based on the lowest score assignment on one criterion for each study crop.

\section{Results and discussion}

Geoinformation mapping is the process of informational mapping and modeling of geosystems [14]. The maps designing is connected with the use of the standard GIS and development of specialized geoinformation systems and new mapping methods, based on them.

The scheme of geoinformation mapping system for quantitative land suitability assessment, composed of several steps, is illustrated in Figure 1.

Physical realization of the trial version of geoinformation mapping system for quantitative land suitability assessment, was carried out in the form of Personal geodatabase for the territory of Agronomic research station of National University of Life 


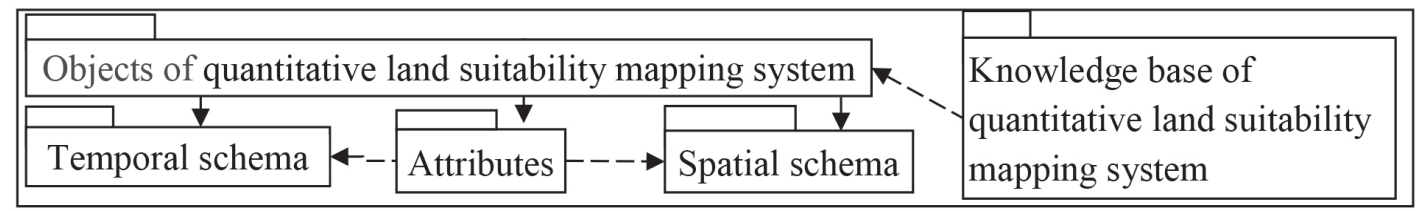

Figure 2 The UML-model of geodatabase packages

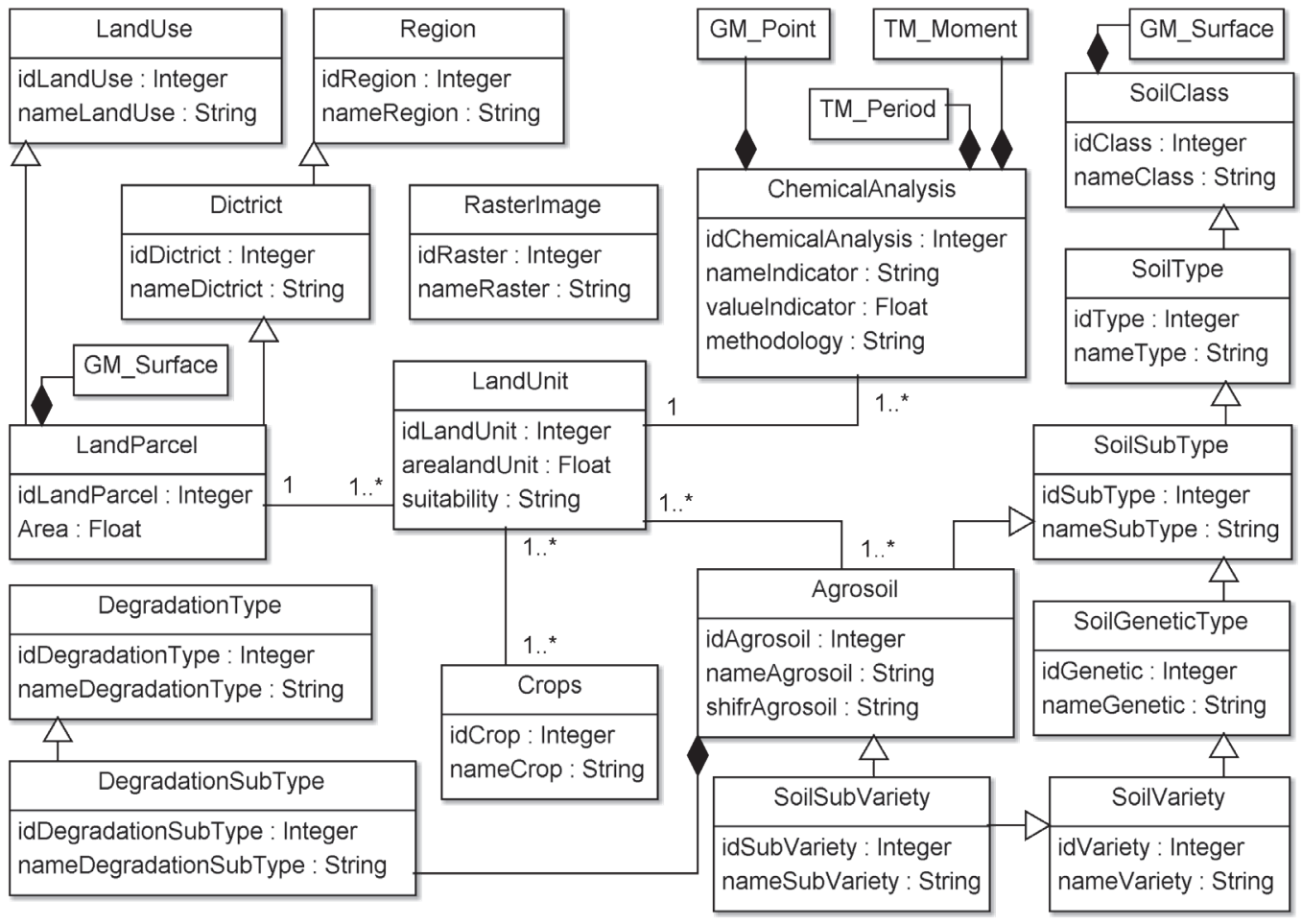

Figure 3 The UML-model of geodatabase classes

and Environmental Sciences of Ukraine, which is located in the Northern Forest-Steppe zone. A set of geoimages, obtained in the research, is based on results of the geoinformation analysis and modeling.

\subsection{Geodatabase}

In general, the geoinformation mapping system for quantitative land suitability assessment could be described as a set of input, intermediate and output data, as well as the processes of data processing, interaction and representation. The input data of the system comprises of non-spatial (attributive) and spatial data. The attributive data included statistical reporting and results of field agrochemical survey. The input data included digital map of soil agricultural production groups (scale 1: 10 000) and digital elevation model (the Shuttle Radar Topography Mission, SRTM).

Large volumes of heterogeneous data require the construction of geodatabase to accumulate, store, analyze spatial information and to create a knowledge base containing descriptions of rules, methods of determination and rules for presentation cartographic materials.

A key feature of geodatabases is the ability to display various data including spatial data. In order to design the conceptual model of geodatabase, the following models have been developed
(Figure 2): the scheme of non-spatial characteristics (attributes) of objects (according to the ISO 19110 Geographic information - Methodology for feature cataloguing); the schema of spatial representation of objects, expressed by geometric primitives (according to ISO 19107 Geographic information - Spatial scheme), and the timing representation of spatial information (according to ISO 19108 Geographic information - Temporal scheme).

The land suitability for crop cultivation strongly depends on the soil quality. Such soil characteristics as $\mathrm{pH}$, hydrolizable nitrogen, available phosphorus and exchangeable potassium, were mapped for each soil unit within the study area in order to obtain a set of intermediate cartographic models.

The model of conceptual geodatabase design of geoinformation mapping system is illustrated in Figure 3.

\subsection{The knowledge base of geoinformation mapping system}

Geoinformation mapping system for quantitative land suitability assessment requires creating a set of complex thematic maps for visualization of the real soil status. In this concern, each mapping object has rules of description, methods of determination, rules for representing the cartographic material 


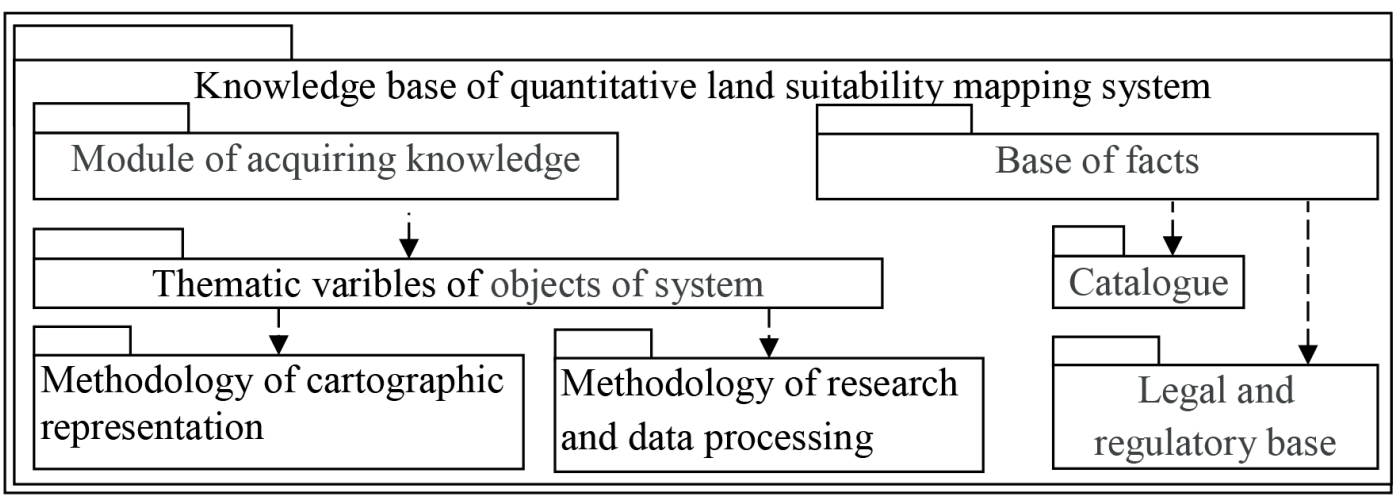

Figure 4 The UML-model of Knowledge base packages

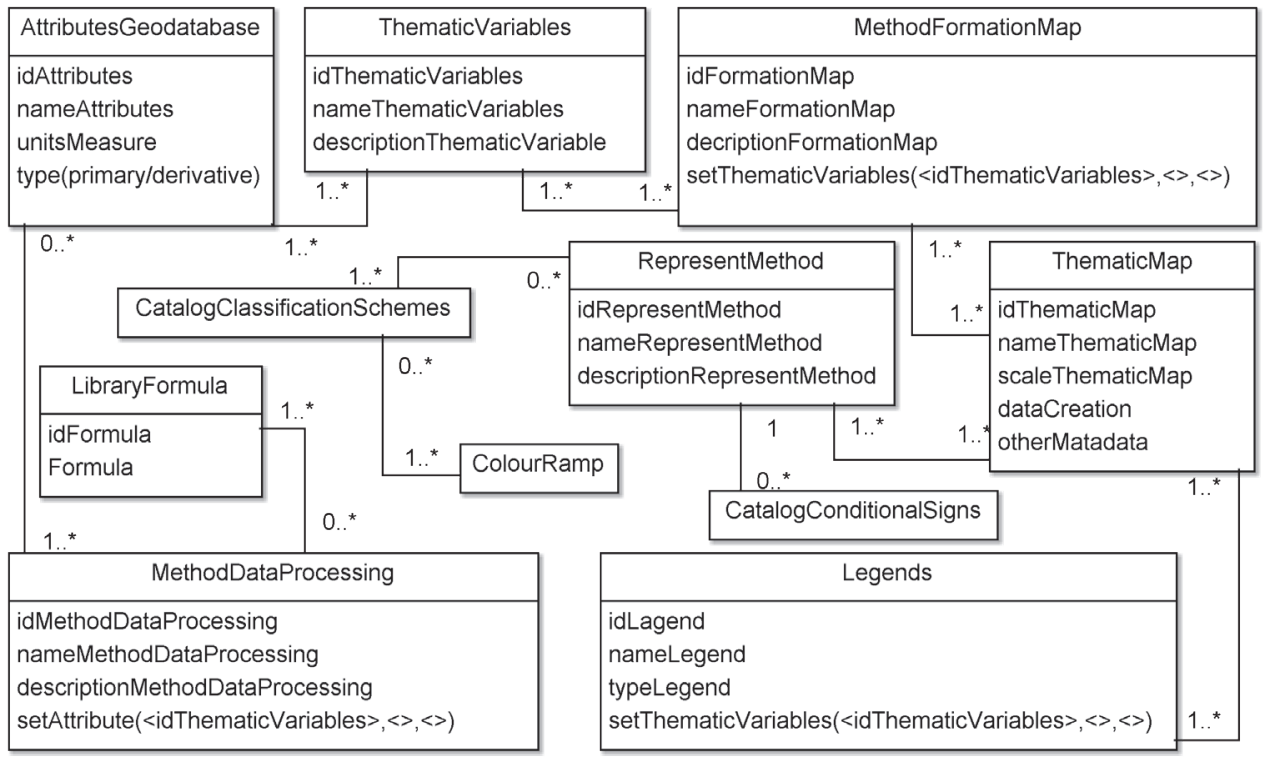

Figure 5 The UML-model of knowledge base classes of quantitative land suitability mapping system

and a set of rules for spatial analysis [12], [15], [21]. These elements are structured with knowledge base [17]. The knowledge base provides development of unified and formalized sets of complex digital thematic maps in the GIS environment.

Structural elements of the process of knowledge base development is shown in Figure 4 by the UML-model of Knowledge base packages.

For each attribute, the appropriate classifiers and codifiers were organized. A set of catalogs and rules of knowledge base and their structure has been defined. It unifies the information, methods of data processing and data representation, determines the set and composition of metadata, as well as rules of cartographic representation of objects (Figure 5).

The following catalogs of the main components of this model are represented by catalog of attributes, methods of data processing, mapping variables, legends, methods of graphical representation (classification schemes, colour ramps).

\subsection{Land suitability mapping}

The input data of geoinformation mapping system for the quantitative land suitability evaluation comprised of statistical reporting and results of field agrochemical survey, map of soil agricultural production groups, digital elevation model (DEM) and slope map, derived from the DEM. Basic maps of the research area are shown in Figure 6. Slopes are represented to be less than 1 degree. Soils belong to the following soil agricultural production groups: 53g - Chernozem typical and Chernozem strongly regraded; $121 \mathrm{~g}$ - Chernozem-like soil; $133 \mathrm{~g}$ - Meadow soil; 141/142 Meadow-boggy soils, undrained/drained; 215g Degraded soils. The group of degraded soils is not involved in crop cultivation being under pastures. Criteria for the crop suitability assessment are represented in Table 1. Values were scaled according to Chirikov method for both $\mathrm{P}_{2} \mathrm{O}_{5}$ and $\mathrm{K}_{2} \mathrm{O}$, and $\mathrm{N}$ according to Kornfield [22].

The classification is known to be one of the most general methods for visualization of analyzed results of spatial and nonspatial data. In order to determine the land suitability for crop cultivation, the classification procedure has been combined with overlay analysis (the AND operation) according to the following sub-classes: S1 - the most suitable lands; S2 - lands with moderate suitability; S3 - limited suitability; S4 - low suitability; $\mathrm{N}$ - unsuitable lands. Since the criteria are measured on different scales, the factors were standardized with linear scaling before combination, so that all the factor maps are correlated with suitability. 
Table 1 Criteria for crop suitability assessment (ppm for $\mathrm{N}_{2} \mathrm{P}_{2} \mathrm{O}_{5}$ and $\mathrm{K}_{2} \mathrm{O}$ )

\begin{tabular}{|c|c|c|c|c|c|c|}
\hline & Criteria & $\begin{array}{c}\text { S1 } \\
\text { high }\end{array}$ & $\begin{array}{c}\mathrm{S} 2 \\
\text { moderately }\end{array}$ & $\begin{array}{c}\text { S3 } \\
\text { marginally }\end{array}$ & $\begin{array}{c}\text { S4 } \\
\text { low }\end{array}$ & $\begin{array}{c}\mathrm{N} \\
\text { not suitable }\end{array}$ \\
\hline \multirow{4}{*}{ 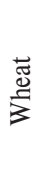 } & $\mathrm{N}$ & $>175$ & $151-175$ & $76-150$ & $35-75$ & $<35$ \\
\hline & $\mathrm{P}_{2} \mathrm{O}_{5}$ & $>100$ & $76-100$ & $61-76$ & $23-60$ & $<22$ \\
\hline & $\mathrm{K}_{2} \mathrm{O}$ & $>100$ & $81-100$ & $41-80$ & $31-40$ & $<30$ \\
\hline & $\mathrm{pH}$ & $6.3-7.3$ & $6.0-6.3 / 7.3$ & $5.8-6.0 / 7.4$ & $4.5-5.8 / 7.5$ & $<4.5 />7.5$ \\
\hline \multirow{4}{*}{ 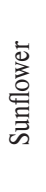 } & $\mathrm{N}$ & $>190$ & $166-190$ & $101-165$ & $40-100$ & $<40$ \\
\hline & $\mathrm{P}_{2} \mathrm{O}_{5}$ & $>100$ & $91-100$ & $51-90$ & $23-50$ & $<22$ \\
\hline & $\mathrm{K}_{2} \mathrm{O}$ & $>200$ & 186-200 & 101-185 & $50-100$ & $<50$ \\
\hline & $\mathrm{pH}$ & $6.0-6.8$ & $5.8-6.0 / 6.9-7.0$ & $5.5-5.8 / 7.1-7.3$ & $5.0-5.5 / 7.4-7.5$ & $<5.0 />7.5$ \\
\hline \multirow{4}{*}{ छే } & $\mathrm{N}$ & $>190$ & 166-190 & $101-165$ & $40-100$ & $<40$ \\
\hline & $\mathrm{P}_{2} \mathrm{O}_{5}$ & $>100$ & $91-100$ & $51-90$ & $23-50$ & $<22$ \\
\hline & $\mathrm{K}_{2} \mathrm{O}$ & $>200$ & $186-200$ & 101-185 & 50-100 & $<50$ \\
\hline & $\mathrm{pH}$ & $6.0-6.8$ & $5.8-6.0 / 6.9-7.0$ & $5.5-5.8 / 7.1-7.3$ & $5.0-5.5 / 7.4-7.5$ & $<5.0 />7.5$ \\
\hline
\end{tabular}
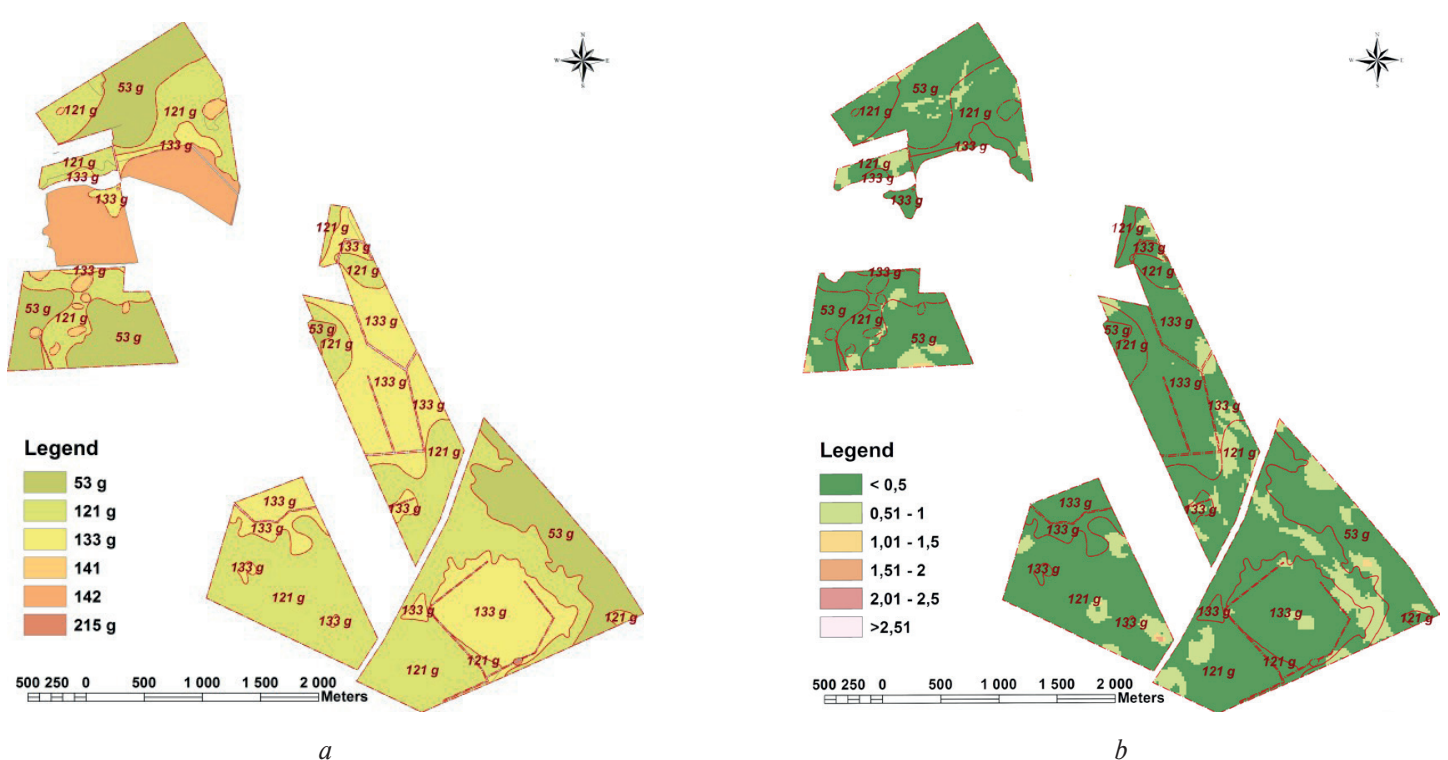

Figure 6 Basic maps: $a$-soil agricultural production groups, $b$-slopes (degree)

According to the land suitability classification [20] the study area belongs to S1 and S3 sub-classes for winter wheat cultivation, however the four sub-classes ( $\mathrm{S} 1$ to $\mathrm{S} 4$ ) are determined by classification based on the soil quality characteristics being mainly represented by the sub-classes with limited and low suitability lands. The same results are achieved to specify the land suitability areas for corn and sunflower.

The lowest score on one criterion has been assigned (according to Table 1) for each study crops. Two criteria - both $\mathrm{pH}$ and $\mathrm{K}_{2} \mathrm{O}$ were the most sensitive criteria, which causes suitability class modification from S3 to S4. S1 and S2 were relatively stable classes despite a certain degree of variations in the values of $\mathrm{N}$, $\mathrm{P}_{2} \mathrm{O}_{5}, \mathrm{~K}_{2} \mathrm{O}$ and $\mathrm{pH}$ (Figure 7). Designed maps characterize the threshold status of the soil quality to provide yields of studied crops on certain areas.

\section{Conclusions}

The process of developing the structure of geoinformation mapping system has been defined by a set of attributes of the soil unit objects. Temporal and spatial characteristics of objects have been established being the basis of the conceptual model of geodatabase. In addition, the possibility of recording data into the geodatabase, related to soil properties and those of being based on agrochemical survey and characterized soil in terms of agrochemical indicators, has been taken into account.

The knowledge base of geoinformation mapping system includes the following components as thematic variables of geoinformation mapping objects: set of research methods, methods of data processing, methods of cartographic representation and spatial analysis. The structure and composition of the knowledge base library and rules of geoinformation mapping system has have been determined in the study.

Application of the geoinformation mapping approaches, based on the constructed knowledge base, provides creating a set of land suitability maps. The developed structure of the knowledge base could be the basis for creating a set of actual land suitability maps.

A number of multi-criteria evaluation methods has been introduced in the GIS environment. Two approaches - overlaying with the AND operation and the lowest score assignment on 


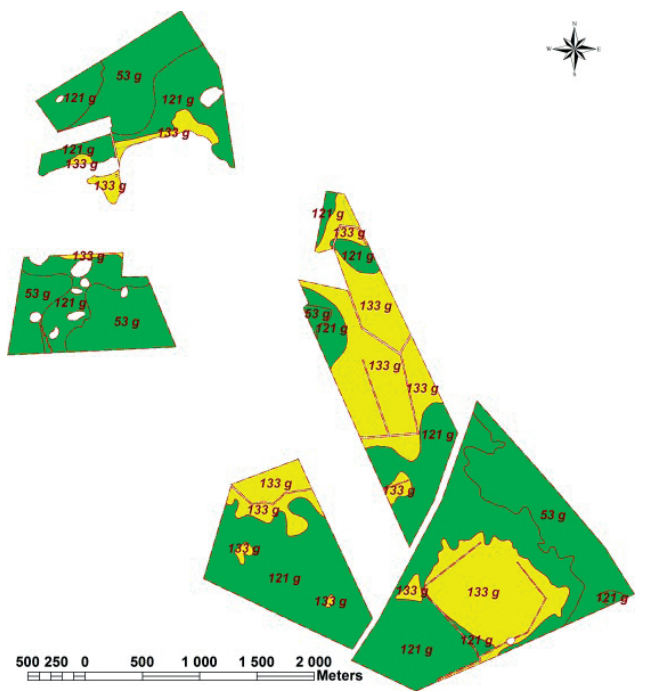

$a$
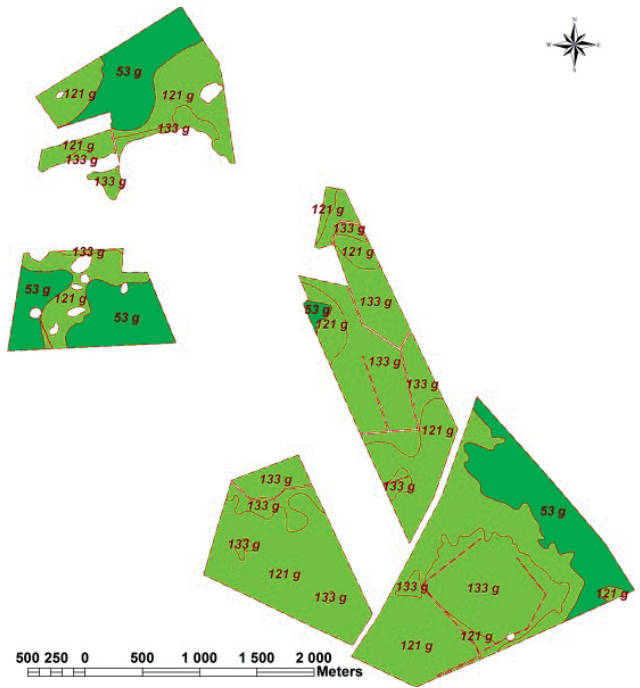

c
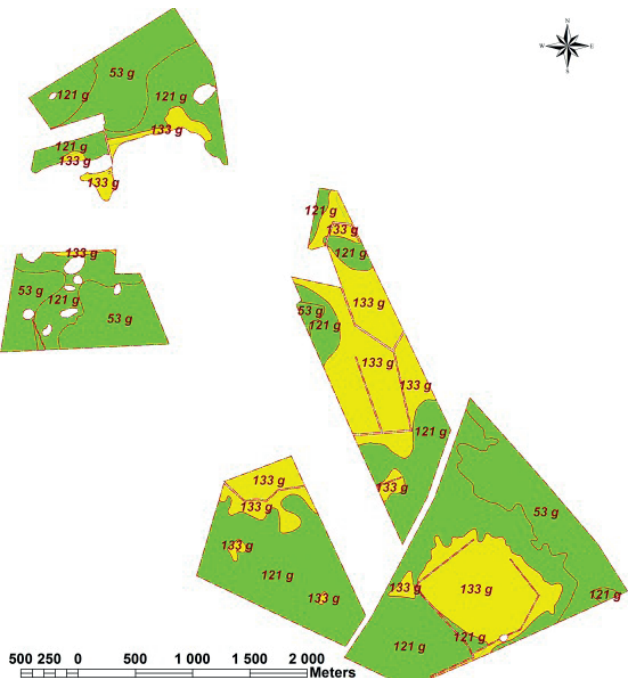

S1

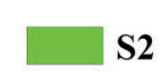

S2

Figure 7 Land suitability maps: a - winter wheat (according to soil

c - corn (according to soil groups); $d$ - corn (according to soil quality); e - sunflower (according to soil groups); $f$ - sunflower (according to soil quality)

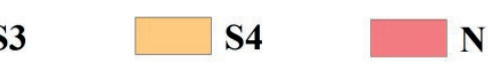

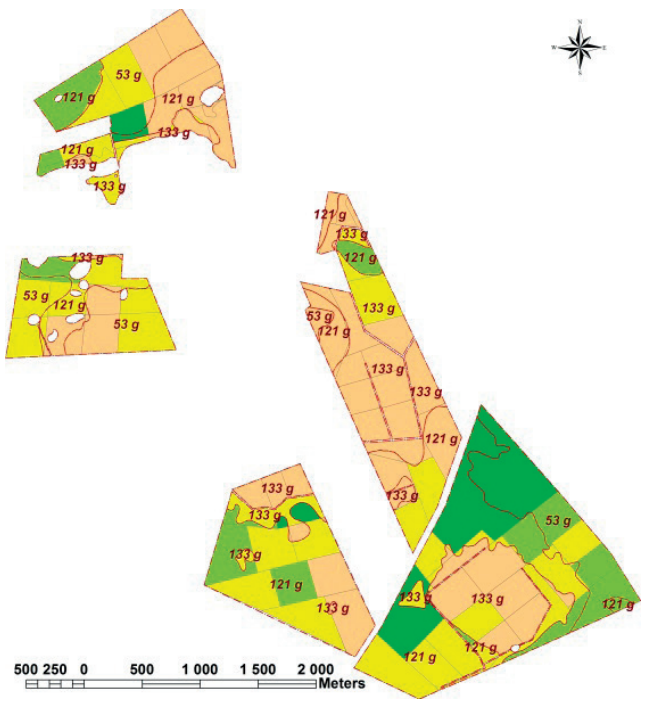

$b$

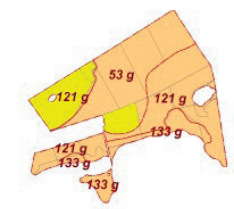

*.
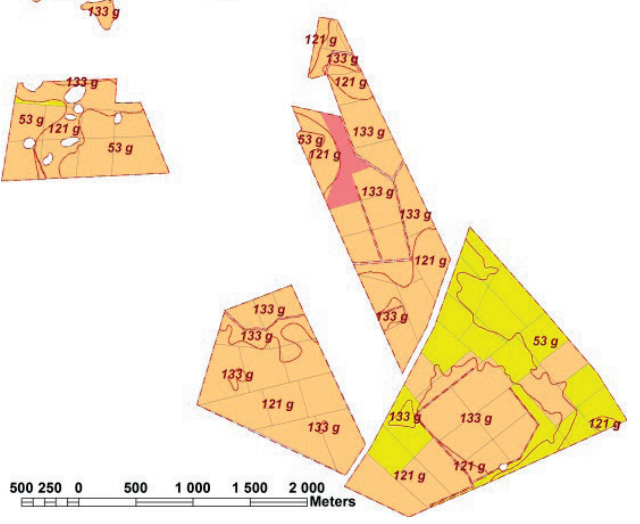

d

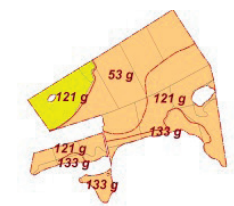

米
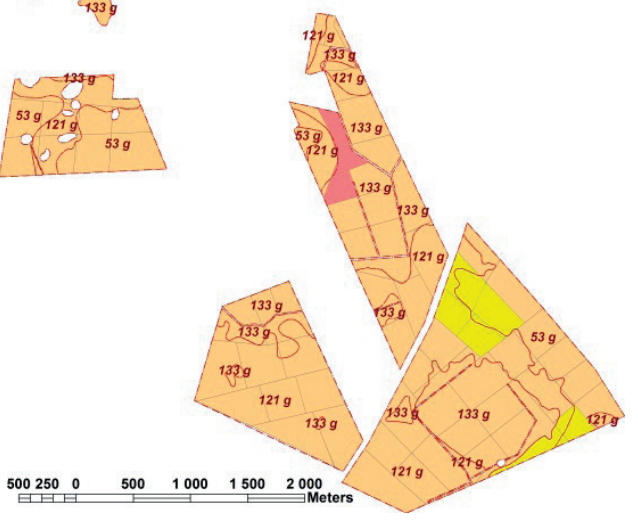

$f$

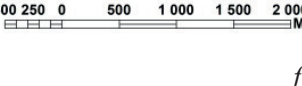


one criterion were used in the study. Results demonstrated that at certain locations, a range of criteria values, according to the AND operations had the lower applicability and less flexibility than according to the second approach, based on the lowest score assignment on one criterion. The results presented in this paper have demonstrated the application of both approaches within a GIS for determining the land suitability areas for the studied crops.

There are still some topics, related to the multi-criteria decision analysis, that should be explained, improved and developed. Those are methods of attribute aggregation, weighing techniques, standardization of factors, error estimation and fuzzy analysis.

\section{References}

[1] FAO. A Frame Work for Land Evaluation. Soils Bulletin, 32 [online]. Rome, 1976. Available: http://www.fao.org/docrep/x5310e/ x5310e00.HTM_1976.

[2] VAN RANST, E., DEBAVEYE, J.: Land Evaluation Part I, Principles in Land Evaluation and Crop Production Calculation. Agricultural Publication, No. 7. General Administration for development cooperation, Brussels, Belgium, 1991.

[3] AHAMED, T. R. N., RAO, K. G., MURTHY, J. S. R.: GIS-Based Fuzzy Membership Model for Crop-Land Suitability Analysis. Agricultural Systems, 63, 75-95, 2000.

[4] CROsetTO, M., TARANTOLA, S: Uncertainty and Sensitivity Analysis: Tools for GIS-Based Model Implementation. International Journal of Geographical Information Science, 15(5), 415-437, 2010. https://doi.org/10.1080/13658810110053125

[5] MALCZEWSKI, J.: GIS-Based Land-Use Suitability Analysis: A Critical Overview. Progress in Planning, 62(1), 3-65, 2004. https://doi.org/10.1016/j.progress.2003.09.002

[6] SENES, G., TOCCOLINI, A.: Sustainable Land-Use Planning in Protected Rural Areas in Italy. Landscape and Urban Planning, 41, 107-117, 1998. https://doi.org/10.1016/S0169-2046(97)00064-9

[7] WU, F.: SimLand: A Prototype to Simulate Land Conversion through the Integrated GIS and CA with AHP-Derived Transition Rules. Geographical Information Science, 12(1), 63-82, 1998.

[8] CHEN, Y., YUA, J, KHAN, S.: Spatial Sensitivity Analysis of Multi-Criteria Weights in GIS-Based Land Suitability Evaluation. Environmental Modelling and Software, 25(12), 1582-1591, 2010. https://doi.org/10.1016/j.envsoft.2010.06.001

[9] CARVER, S. J.: Integrated Multi-Criteria Evaluation with Geographical Information Systems. International Journal of Geographical Information Systems, 5(3), 321-339, 2007. https://doi.org/10.1080/02693799108927858

[10] VAN LIER, H.: The Role of Land Use Planning in Sustainable Rural Systems. Landscape and Urban Planning, 41(2), 83-91, 1998.

[11] KARPINSKI, Y., LYASCHENKO, A.: Content and Means of Modern Geo-Mapping. Proceedings of International ScientificPractical Conference "Integration of geospatial data in studies of natural resources", Ukraine, 72-76, 2014.

[12] BULYGIN, S., ACHASOV A.: Using GIS Technology for Soil Mapping, Bulletin of Agricultural Science, 10, 52-56, 2012.

[13] KARPINSKI, Y., LYASCHENKO, A., RUNETS, R.: Reference Model of Topographic Database. Bulletin of Geodesy and Mapping, 2, 28-36, 2010.

[14] LYASCHENKO, A., CHERIN, A.: Architecture Modern GIS Based on Spatial Databases. Bulletin of Geodesy and Mapping, 5, 45-50, 2010.

[15] ZATSERKOVNYY, V., KRIVOBERETS, S.: Analysis of GIS Technology Possibilities to Monitoring of Arable Land. Chernihiv Scientific Journal, Series 2, Engineering and Nature, 2(2), 88-94, 2011.

[16] KOKHAN, S., MOSKALENKO, A.: Development of Knowledge Base Structure of Geoinformation System for Evaluation of Quality Status of Agricultural Lands. Eastern-European Journal of Enterprise Technologies, 5(2), 32-37, 2015.

[17] MOHD, S. A., EVANS, A., BENEST, I., KIMBLE, C.: Modelling Knowledge-Based Systems Using UML Profile [online]. Available: http://www.chriskimble.com/Publications/Documents/Abdullah_2004b.pdf.

[18] SIGOV, A., NECHAEV, V., KOSHKAREV, M.: Architecture Subject-Oriented Knowledge Base of Intellectual. International Journal of Open Information Technologies, 2(12), 1-6, 2014.

[19] ZAGORULKO, Y.: On the Concept of the Integrated Model of Knowledge Representation. Bulletin of the Tomsk Polytechnic University, 5(322), 98-103, 2013.

[20] DOBRYAK, D., KANASH, O., BABMINDRA, D., ROZUMNYI, I.: Classification of Agricultural Lands as Scientific Prerequisite of their Ecological Secure Use. Urozhay, Kyiv, 248-447, 2009.

[21] KOKHAN, S., MOSKALENKO, A., SHILO, L.: Geoinformation Service of Soil Quality Evaluation. Eastern-European Journal of Enterprise Technologies, 6(3), 18-25, 2013.

[22] GORODNIY, M.: Agrochemistry: Manual, the $4^{\text {th }}$ edition. Aristey, Kyiv, 138-145, 2008. 